\title{
Modelling Landside Logistic Operations of a Mega-hub Airport with Discrete-event Simulation
}

\author{
Rodrigo Romero-Silva ${ }^{1 *}$, Miguel Mujica Mota ${ }^{2}$ \\ ${ }^{1}$ Deapartment of Operations Analytics, Vrije Universiteit Amsterdam, De Boelelaan 1105, 1081 HV, Amsterdam, \\ The Netherlands; *r.romerosilva@vu.nl \\ ${ }^{2}$ Aviation Academy, Amsterdam University of Applied Sciences, Weesperzijde 190, 1097 DZAmsterdam, \\ The Netherlands
}

SNE 31(3), 2021, 111-120, DOI: 10.11128/sne.31.tn.10571 Received: March 10, 2021 (Selected EUROSIM 2019 Postconf. Publ.), Revised: August 31, 2021; Accepted: September 3, 2021 SNE - Simulation Notes Europe, ARGESIM Publisher Vienna, ISSN Print 2305-9974, Online 2306-0271, www.sne-journal.org

Abstract. The need to better understand how to manage the real logistics operations in Schiphol Airport, a strategic hub for the economic development of the Netherlands, created the conditions to develop a project where academia and industry partnered to build a simulation model of the Schiphol Airport Landside operations. This paper presents such a model using discrete-event simulation. A realistic representation of the open road network of the airport as well as the (un)loading dock capacities and locations of the five ground handlers of Schiphol Airport was developed. Furthermore, to provide practitioners with applicable consolidation and truck-dispatching policies, some easy-to-implement rules are proposed and implemented in the model. Preliminary results from this model show that truck-dispatching policies have a higher impact than consolidation policies in terms of both distances travelled by cooperative logistic operators working within the airport and shipments' average flow time. Furthermore, the approach presented in this study can be used for studying similar mega-hubs.

\section{Introduction}

Airports are one of the most critical nodes in international trade networks as well as critical hubs for the economic development of a country. Since international airports concentrate a great proportion of cargo value flow into and out of a country (35\% of global cargo flows based on value - [1]), the operational performance of an airport is a key factor in the logistic capabilities of a nation and, consequently, in the competitive advantage of a country with respect to other nations [2].
In Europe, the proportion of weight moved by air is $0.8 \%$ compared with the $26.7 \%$ value of goods of all transport modes [3]; for this reason, airports attain added value with logistics operators with a better flow of goods, i.e. shorter throughput times, instead of exclusively through price competition. Thus, it is increasingly important for international cargo airports to improve their performance in terms of throughput times without a high impact on the costs of moving cargo through their facilities.

Air cargo hub operations (air cargo terminal operations - [4]) can be divided into two main systems: the landside and the airside. Landside operations deal with the interchange of cargo between logistics operators and the airport's ground handlers $(\mathrm{GH})$, which receive cargo from the landside, sort the cargo and then deliver it to the corresponding aircraft (the airside). Landside operations are notoriously difficult to manage as they are comprised of various interconnected and interdependent processes and many agents with possible conflicting goals, as will be explained in the next section. Because of this, many studies have investigated some parts of the problem in a separate manner, e.g., logistics provider freight consolidation [5] or truck scheduling at ground handler terminals [6]; however, to the best of our knowledge, a systemswide investigation of the landside air cargo terminal operations has not been developed.

This study is concerned with investigating how the Schiphol Airport landside operations (SALO) can be improved with a decision support system that uses a more realistic representation of the system, in contrast with more idealistic models. Owing to the complexities and characteristics of the problem, this system was modelled using discrete-event simulation (DES), as previous studies on complex systems have previously done $[7,8]$.

Furthermore, dynamic policies of shipment consolidation and resource sharing were considered to improve the performance of the system since a static-deterministic 
optimization approach was deemed inapplicable to solve such a dynamic and stochastic environment.

The remainder of the paper is organized as follows. In Section 1 a description of the problem at hand is developed. Section 2 presents a short review of the literature related to this study. The methodological approach of the study is explained in Section 3. Section 4 shows the results of the simulation study, while Section 6 presents the discussion and conclusions of the paper.

\section{Problem Description}

To illustrate the problem at hand, first, we explain the process of an outbound shipment. An outbound shipment could arrive at the air cargo terminal through two main channels. The first one is via a logistics operator with no physical presence within the airport - external logistics operator (ELO). These shipments arrive in a truck directly to the ground handlers' locations where a dock is assigned to the truck and the truck is parked in the dock. Then, the shipment is unloaded and stored in the GH's warehouse until the sorting of shipments for the airside takes place.

The second channel is via a logistics operator with warehousing facilities inside the airport - internal logistics operator (ILO). When a shipment comes through an ILO, it first arrives at the warehouse of the ILO for further consolidation. ILOs need this final step of consolidation because they deliver shipments to different locations (depending on the number of $\mathrm{GH}$ ) in some airports and, thus, the final route for different shipments can vary, depending on the needed time of delivery (related to flight departure time) and the final delivery point. Therefore, whenever the shipment is ready for delivery, an ILO-managed truck is dispatched to the corresponding $\mathrm{GH}$ for delivery, where it must pass the same process as ELO-managed trucks.

In the case of inbound shipments using an ILO, the inverse trip occurs: after the shipment is ready to be picked up from the GH warehouse, it waits for an ILO truck to be picked up. An ILO truck will be dispatched to pick up a shipment, depending on the urgency of the shipment or on an already programmed visit to that specific GH location. Then, the ILO truck will wait to be assigned a loading dock, park in the dock, and load the shipment, after which the shipment will travel to the ILO warehouse to be stored, sorted, and further consolidated for its next destination outside the airport. In the case of an ELO shipment, it will only be picked up by a truck and then leave the airport for a long-haul trip, with the corresponding visit (and possible waiting) to the GH's loading docks.

Following this description, the problem of the landside operations of an air cargo terminal can be described by the dual problem of the planning of the ILO routes for picking-up and delivering shipments while also managing the workload in the GH's docks since very frequent routes between ILO and GH warehouses, i.e. minimal consolidation, could result in a higher workload for the docks and more travelling costs due to repeated, multiple visits; whereas a reduced dock workload and transportation costs could result from more infrequent routes, i.e. more consolidation, but with the trade-off of higher throughput times and possible late deliveries. In addition, an inefficient consolidation would cause an increase in greenhouse emissions which have gained a more important role everywhere as a decision variable to consider when managing transport systems.

To make the previous problem more complex, inbound and outbound arrivals both from ELO and ILO shipments arrive at the system in a dynamic and stochastic manner as some of the shipments arrive unannounced and some others, despite a previous announcement from the logistic operators, arrive at different times and weights than previously announced. Thus, the management of the landside operations of an air cargo terminal is comprised of three interconnected decisions: (i) how shipments are consolidated, (ii) how often consolidated shipments are dispatched, and (iii) which routes should be used to pick up and deliver the cargo.

\section{Related Literature}

As previously mentioned, landside air cargo terminal operations are a set of interconnected, separate problems. However, since no study has considered these problems jointly, this section will review some of the papers that have tackled each one of the pertaining problems individually in order to better understand the nature and complexity of the problem and summarize previous findings.

The most traditional approach for addressing decisions (i) and (ii) (see section 1) has been to use a decision policy for a non-capacitated vehicle dispatching based on three shipment-consolidation policies: quantity, time, and time-quantity [9]. In a quantity-based shipment consolidation policy, the decision of whether to dispatch a vehicle is taken based on the amount of weight or units, e.g., boxes, that have been accumulated to be transported up until the decision point. 
It is highly related to the economic order quantity [10]. On the contrary, a time-based policy depends on the time that has passed since the decision period began, e.g., since the beginning of the day or since the last vehicle dispatch; therefore, a vehicle is only dispatched when a specific period has been reached. Vehicles are dispatched with the available consolidated shipments depending on which of the two thresholds, i.e. quantity or time, is reached first.

Most of the literature that has studied these shipmentconsolidation policies [9,11-14] agree that the quantitybased policy is superior in terms of cost minimization to the time-based policy in most instances (even when considering two classes of customers with different priorities - [15]) as this policy finds a good trade-off between inventory holding costs and transportation costs (caused by the number of dispatches). However, some studies have suggested that a time-quantity combined policy could have a better performance in terms of maximum waiting times and average order delay than the quantity-based policy [16], as it has been found to have a subpar performance in terms of customer satisfaction due to late and long delivery times.

Using Battarra et al.'s classification [17], most of the studies concerned with these issues have focused on 1-1 problems, where only one product and commodity needs to be transported from one origin to one destination, although, in general, the actual trip to the destination is not modelled and only the decision in the origin point is taken into account. A notable extension to this simple problem can be found in [18], where they suggest some simple rules-of-thumb for a 1-1 shipment consolidation problem with a capacitated vehicle.

Decision (iii) (see section 1), i.e. which routes to use, on the other hand, has been generally studied with an optimization approach by building routes for delivering and picking up products in a set of nodes using one or many vehicles in order to optimize an objective function, commonly associated with minimizing transportation costs, i.e. distance travelled. While most of the research has focused on a deterministic and static problem [19], stochastic and dynamic VRP are more relevant for the current practice and for this current study as transport requests arrive dynamically to a variety of logistic systems and the actual demand to be transported from point to point and the nodes to be served are random variables.

According to Pillac et al. [20], dynamic problems have been solved with different solution approaches.
Considering a dynamic but deterministic scenario, previous work has used both periodic and continuous reoptimization strategies to cope with the dynamism of the problem. While periodic re-optimization uses a static approach to generate routes at decision intervals, continuous re-optimization generates routes every time the state of the system changes, e.g., a new order arrives. Thus, as continuous re-optimization constantly updates the routes of each vehicle with the latest information, this approach could be difficult to implement in some environments, as the vehicle only knows the next route whenever they have finished their current request.

Overall, it can be concluded that the problem at hand, i.e. the landside operations in an air cargo terminal, has not been studied considering all the interconnected and interdependent processes relevant for a good performance of the cargo terminal. Therefore, in this work, we present a modelling framework that distinguishes from previous research by presenting a holistic approach in which the three main decision problems can be studied together, including all the main elements of the described system. Furthermore, it provides a unique and innovative testbed for investigating the relevance of different operational policies to increase the competitive advantage of air cargo terminals.

\section{Conceptual Design for the Implementation of a Discrete- event Simulation Model}

A DES simulation model was built by coupling two layers, a GIS layer and, on top of the first layer, the model of Schiphol Airport considering the physical layout of the system, i.e. the roads and warehouse locations. The simulation model was built with Simio software [21] version 10.181 of 64 bits. Thus, a network composed of nodes and edges with functionalities that represented roads was built over the actual roads represented on the GIS map connecting all the relevant logistic points of SALO.

The landside of the cargo terminal of Schiphol Airport has five different ground handlers operating in the facilities of the airport [22]. Table 1 shows the proportional flow that each $\mathrm{GH}$ receives both for inbounds (I-GH) and outbounds (O-GH) (based on real Air-Way Bill (AWB) data from 30 days of November 2017) as well as the number of (un)loading docks considered per GH (based on GH's data and visits to GH's facilities). Both ILO and ELO pick up and deliver goods at those five different locations. 
Furthermore, more than 100 logistic operators work with airlines departing and arriving at Schiphol while several individual trucking companies service those logistic operators. Because of the difficulty to manage and control all these firms to improve operations, it was decided to divide shipment arrivals into two stream categories depending on the degree of operational control that can be implemented into the firms: ILO shipment arrivals and ELO truck arrivals. ILO shipment arrivals are shipments that arrive at the airport via the most important ILOs operating within the surroundings of the Schiphol airport, based on the total number of inbound and outbound AWB.

ILO shipment arrivals were modeled in this study as individual AWBs arriving at ILO's warehouses to be further consolidated and transported to the corresponding GH destination (and vice-versa). Table 2 describes the process that was used to generate ILO shipment arrivals as well as the average rate of AWB arrivals considered for this model (based on real data).
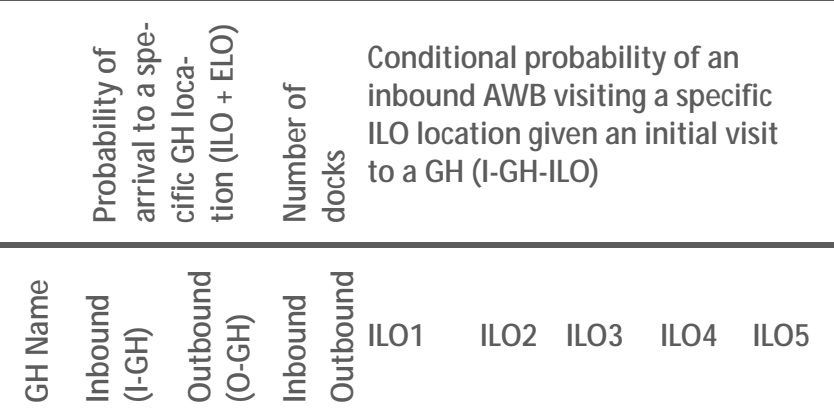

\begin{tabular}{|c|c|c|c|c|c|c|c|c|c|}
\hline $\begin{array}{l}\text { GH } \\
1\end{array}$ & 0.6050 & 0.5285 & 12 & 12 & 0.7885 & 0.0840 & 0.1005 & 0.0000 & 0.0269 \\
\hline $\begin{array}{l}\text { GH } \\
2\end{array}$ & 0.1444 & 0.1494 & 8 & 8 & 0.3512 & 0.1628 & 0.2583 & 0.1612 & 0.0665 \\
\hline $\begin{array}{l}\text { GH } \\
3\end{array}$ & 0.1104 & 0.1008 & $\begin{array}{l}14( \\
\text { shar }\end{array}$ & $\begin{array}{l}\text { (1/0 } \\
\text { red) }\end{array}$ & 0.2258 & 0.4194 & 0.0000 & 0.1935 & 0.1613 \\
\hline $\begin{array}{l}\text { GH } \\
4\end{array}$ & 0.0507 & 0.0838 & $\begin{array}{l}11 \text { ( } \\
\text { shar }\end{array}$ & $\begin{array}{l}\text { 1/0 } \\
\text { red) }\end{array}$ & 0.0006 & 0.4572 & 0.0006 & 0.3092 & 0.2323 \\
\hline $\begin{array}{l}\text { GH } \\
5\end{array}$ & 0.0895 & 0.1375 & 10 & 7 & 0.0003 & 0.3641 & 0.0006 & 0.3220 & 0.3131 \\
\hline
\end{tabular}

Table 1: Proportion of flows from and to the GHs.

Five ILOs were selected to be modeled in this category as they represented $16 \%$ of total cargo flow. Table 2 shows the probability that an outbound AWB arrived at a specific ILO location (O-ILO) as well as the conditional probability that an outbound AWB will visit a $\mathrm{GH}$, given an initial visit to an ILO (O-ILO-GH). The probability of an inbound AWB visiting an ILO location, given an initial visit to a GH (I-GH-ILO) can be found in Table 1. $\rightarrow$ ILO individual shipments identified by an AWB (AirWayBill) number are generated based on the pattern and rate of arrivals of either outbound (9.32 AWB per hour on average) or inbound (25.86 AWB per hour) flow.

$\rightarrow$ Random initial node destination is assigned to AWB based on flow proportions.

$>$ If inbound, initial GH node is assigned based on data from Table 1 (I-GH).

$>$ If outbound, initial ILO node is assigned based on data from Table 2 (0-ILO).

$\rightarrow$ Random final node destination is assigned to AWB based on flow proportions.

$>$ If inbound, final ILO node is assigned based on initial $\mathrm{GH}$ node using data from Table 1 (I-GH-ILO), e.g., if initial node was $\mathrm{GH} 2$, then data from the second row will be used to define the probabilities of the AWB's final ILO node.

$>$ If outbound, final $\mathrm{GH}$ node is assigned based on initial ILO node using data from Table 2 (0-ILO-GH), e.g., if initial node was ILO3, then data from the third row will be used to define the probabilities of the AWB's final GH node.

$\rightarrow$ Weight of AWB is randomly assigned based on historic data.

$>\quad$ If inbound, exponential distribution with mean $683 \mathrm{~kg}$.

$>$ If outbound, exponential distribution with mean $271 \mathrm{~kg}$.

$\rightarrow$ Register AWB's arrival time and randomly assign due date (DD).

$>$ Weibull distribution with parameters $\lambda=8$ hours (range) and k =5 (shape).

$\rightarrow$ Decide whether AWB is a rush order:

$>$ IF DD $<4$ hours THEN AWB is a rush order

$\rightarrow$ If inbound shipment, AWB is sent to GH node and waits to be consolidated with other AWBs, depending on the AWB consolidation and truck dispatching policies.

$\rightarrow$ If outbound shipment, AWB is sent to ILO node and waits to be consolidated with other AWBs, depending on the AWB consolidation and truck dispatching policies

Table 2: Pseudo-code to generate ILO shipment's arrivals.

On the other hand, ELO administered shipments were modelled as consolidated shipments to be picked up (or delivered) by one single truck and, thus, only visited one $\mathrm{GH}$ location. It was further assumed that ELO were not collaborating with consolidation efforts inside SALO and thus no specific control over their visits to GH locations could be made. The logic behind the process of generating ELO shipments can be found in Table 4. ELO shipments were represented in the model as truck arrivals following a time-varying Poisson process [23] with a random percentage of the flow. 


\begin{tabular}{|c|c|c|c|c|c|c|}
\hline \multirow[t]{2}{*}{$\begin{array}{l}\sum^{10} \\
\frac{10}{2} \\
9\end{array}$} & \multirow{2}{*}{ 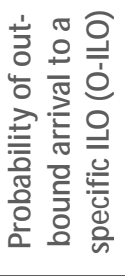 } & \multicolumn{5}{|c|}{$\begin{array}{l}\text { Conditional probability of an outbound } \\
\text { AWB visiting a specific GH location given } \\
\text { an initial visit to an ILO (0-ILO-GH) }\end{array}$} \\
\hline & & GH1 & GH2 & GH3 & GH4 & GH5 \\
\hline ILO1 & 0.1660 & 0.2350 & 0.3968 & 0.3524 & 0.0014 & 0.0144 \\
\hline ILO2 & 0.2497 & 0.0050 & 0.0269 & 0.1402 & 0.4238 & 0.4040 \\
\hline ILO3 & 0.2472 & 0.0072 & 0.2429 & 0.1458 & 0.0104 & 0.5937 \\
\hline ILO4 & 0.1546 & 0.0285 & 0.1665 & 0.1430 & 0.2243 & 0.4378 \\
\hline ILO5 & 0.1825 & 0.0147 & 0.1419 & 0.1227 & 0.1788 & 0.5419 \\
\hline
\end{tabular}

Table 3: Proportion of flows from and to the ILOs.

Truck arrivals occur with a time-varying Poisson mean arrival rate that depends on both the weekday and the hour of the day $[24,25]$ due to work shifts by both trucking and handling companies as well as flight schedules.

$\rightarrow$ Consolidated shipments to be transported by an ELO truck are generated based on pattern and rate of arrivals of either outbound ( 465 trucks per day on average) or inbound (384 trucks per day) flow.

$\rightarrow$ Random GH destination is assigned to ELO-consolidated shipments based on either inbound (I-GH) or outbound (0-GH) proportions shown in Table 1.

$\rightarrow$ Weight of ELO-consolidated shipments (WELO) is assigned randomly.

$>$ Triangular distribution $(\min =0 \mathrm{~kg}$, mode $=5$ $\mathrm{kg}$, $\max =10 \mathrm{~kg}$ ), based on a maximum weight of $10 \mathrm{~kg}$ per truck, which depends on the typical maximum volume carried by trucks inside Schiphol.

$\rightarrow$ Type of containers of ELO-consolidated shipments is assigned randomly.

$>\quad$ Discrete distribution ( $1 / 3$ - ULD, $1 / 3$ - assorted pallets, $1 / 3$ - combined containers).

$\rightarrow$ If inbound shipment THEN ELO-consolidated shipment is sent to the respective $\mathrm{GH}$ node and a signal is sent for an ELO truck to pick up the consolidated shipments.

$\rightarrow$ If outbound shipment THEN ELO-consolidated shipment is generated along with a truck in a node representing an entering road point in the Schiphol Airport landside road network (2 common points for trucks. The truck then carries out the delivery from the entering point to the destination $\mathrm{GH}$ node

Table 4: Pseudo-code to generate ELO shipment's arrivals.

\subsection{Consolidation and truck-dispatching policies}

Due to the dynamism and stochasticity of SALO, it was deemed that a practical way of managing the operations of the system was to implement easy-to-use operating rules instead of inapplicable complex policies and algorithms. Thus, following the shipment consolidation notions from Cetinkaya and Bookbinder [13] and the truckdispatching concepts from Cook and Lodree [18] a series of policies were considered to be applied separately to inbound and outbound shipments. Table 5 describes the general logic behind the consolidation policies (CP) while Table 6 explains the general logic followed by the truck-dispatching policies (TP). Specific logic for both CPs and TPs can be found in Table 7 via a pseudo-code.

\begin{tabular}{|c|c|}
\hline $\begin{array}{l}\text { Consolidation } \\
\text { policy }\end{array}$ & $\begin{array}{l}\text { Set of shipments considered } \\
\text { for consolidation }\end{array}$ \\
\hline $1-1$ & $\begin{array}{l}\text { Only shipments going from one specific } \\
\text { node to another, e.g. GH2 to ILO5 }\end{array}$ \\
\hline $1-N$ & $\begin{array}{l}\text { Shipments to be moved from one single } \\
\text { location to multiple destinations, e.g., } \\
\text { from ILO3 to GH2, GH4 and GH5 for out- } \\
\text { bound shipments; or from GH2 to ILO1, } \\
\text { ILO2, ILO4 and ILO5 for inbound ship- } \\
\text { ments }\end{array}$ \\
\hline N-1 & $\begin{array}{l}\text { Shipments to be moved from multiple } \\
\text { locations to one specific destination, e.g., } \\
\text { from } \mathrm{GH} 1, \mathrm{GH} 2 \text { and GH3 to ILO5 for } \\
\text { inbound shipments; or from ILO3 and } \\
\text { ILO4 to GH3 for outbound shipments }\end{array}$ \\
\hline N-N & $\begin{array}{l}\text { Shipments to be moved from multiple } \\
\text { locations to multiple destinations, e.g. } \\
\text { from ILO2, ILO3, ILO4 and ILO5 to GH1, } \\
\text { GH2 and GH4 for outbound shipments, or } \\
\text { vice-versa for inbound shipments }\end{array}$ \\
\hline
\end{tabular}

Table 5: Shipment consolidation policies.

TPs are inherently associated in this model with CPs as the amount of consolidated weight or number of AWBs to be considered for triggering the TPs will depend on the criteria to consolidate the shipments. For example, if the FT truck-dispatching policy is considered, then a full truck will be calculated based on the accumulated weight of the consolidation policy. Suppose the CP considered is 1-N for inbound shipments, then an FT will be fulfilled only when the total weight accumulated in one GH location to be moved to any set of ILO points is higher than the maximum allowed truckload. This interaction means that the thresholds for dispatching a truck will be reached quicker the more nodes are considered in the consolidation. 
Thus, an N-N policy will consolidate enough weight to dispatch a truck quicker than a $1-\mathrm{N}$ or an $\mathrm{N}-1$ policy; whereas a 1-1 policy will take the longest to consolidate enough AWBs to be able to dispatch a truck.

\begin{tabular}{cl}
\hline $\begin{array}{c}\text { Truck-dispatching } \\
\text { policy }\end{array}$ & $\begin{array}{l}\text { Condition that needs to be } \\
\text { fulfilled to send a signal to } \\
\text { consolidate shipments } \\
\text { (see Table 7 for the full logic } \\
\text { of the policies) }\end{array}$ \\
\hline $\begin{array}{c}\text { CD: Continuous De- } \\
\text { ployment }\end{array}$ & $\begin{array}{l}\text { One truck available for transport- } \\
\text { ing AND at least one AWB ready } \\
\text { to be consolidated }\end{array}$ \\
\hline ESW (Economic Ship- & $\begin{array}{l}\text { Accumulated consolidated weight } \\
\text { is HIGHER than Economic Ship- } \\
\text { ment Weight) } \\
\text { in [9] }\end{array}$ \\
\hline ESW+RAWB & $\begin{array}{l}\text { Accumulated modified consoli- } \\
\text { dated weight is HIGHER than Eco- } \\
\text { nomic Shipment Weight formula } \\
\text { proposed in [9]. This formula } \\
\text { considers rush AWBs (RAWB) } \\
\text { having a higher holding cost than } \\
\text { normal orders }\end{array}$ \\
\hline RAWB (Rush AWBs) & $\begin{array}{l}\text { At least one accumulated RAWB } \\
\text { waiting to be consolidated. This } \\
\text { policy tries to minimize the wait } \\
\text { of RAWBs }\end{array}$ \\
\hline FT (Full Truckload) & $\begin{array}{l}\text { The maximum allowed truckload } \\
\text { of accumulated consolidated } \\
\text { weight has been reached }\end{array}$ \\
\hline
\end{tabular}

Table 6: Truck-dispatching policies.

Since the most common type of truck used to move cargo is the semi-trailer with dimensions $13.6 \times 2.48 \times 2.80 \mathrm{~m}$., it was considered as the single type of truck to move cargo within the model. Based on experts' feedback regarding the typical density of the goods transported in Schiphol air cargo terminal, it was deemed that the maximum weight load used with combined cargo was 10 tons (the actual maximum load was limited by the volume of the goods, not the weight).

Table 8 shows the rules used to calculate the (un)loading times depending on the type of shipment and container. ELO maximum (un)loading times were modeled following experts' advise while ILO maximum times were taken from [26]. Despite the fact that it has been shown that truck loading takes more time than unloading [26], for this exercise it was assumed that loading and unloading required the same effort. $\rightarrow$ Add the weight of the arriving AWB $\left(\mathrm{W}_{\mathrm{AWB}}\right)$ to the accumulated weights of all consolidation policies 1-1, N$1,1-\mathrm{N}$ and $\mathrm{N}-\mathrm{N}$, e.g., $\mathrm{WI}_{\mathrm{gi}}=\mathrm{WI}_{\mathrm{gi}}+\mathrm{W}_{\mathrm{AWB}}$, being that $\mathrm{g}$ is the arriving node and $\mathrm{i}$ is the departing node for the current AWB.

$\rightarrow$ Increase in one the number of AWBs in the counters of all consolidation policies, e.g., $\operatorname{l~}_{g i}=I_{g i}+1$.

$\rightarrow \quad$ IF the arriving AWB is a rush order, add one rush order to the accumulated number of rush orders of all consolidation policies, e.g., $\mathrm{Rl}_{\mathrm{gi}}=\mathrm{RI}_{\mathrm{gi}}+1$.

$\rightarrow \quad I F \mathrm{WI}_{\mathrm{gi}} \geq 10$ tons THEN

$>$ Prepare a pallet with $I_{g i}$ - 1 elements (to ensure the weight is never higher than 10 tons.

> Reset all accumulated weights and counters accordingly.

$>\quad$ Pallet sends request to be picked-up by an ILO truck.

$\rightarrow$ IF ConsolidationPolicy $=$ "1-N"

$>$ IF WI $1 N_{g} \geq 10$ tons (equivalent to TruckDispatchPolicy = "FT") THEN

$\Rightarrow$ Prepare a pallet with I $1 \mathrm{~N}_{\mathrm{g}}-1$ elements.

$\Rightarrow$ Reset all accumulated weights and counters accordingly.

$\Rightarrow$ Pallet sends request to be picked-up by an ILO truck.

$>$ ELSE point towards the TruckDispatchPolicy

$\Rightarrow$ IF TruckDispatchPolicy $=$ "ESW" THEN

- IF $W I I N_{g} \geq \sqrt{\frac{2 D_{g} S(683)}{h}}$, being that $\mathrm{D}_{g}$ is the average of AWB arrivals per hour arriving to node $g$, THEN

- RUN the next sequence called SEQ_1N

- Prepare a pallet with I_ $1 \mathrm{~N}_{\mathrm{g}}$ elements.

- Reset all accumulated weights and counters accordingly.

- Pallet sends request to be picked-up by an ILO truck.

$\Rightarrow \quad$ IF TruckDispatchPolicy $=$ "ESW +DD” THEN

- IF $W I_{-} I N_{g} \geq \sqrt{\frac{2 D_{g} S(683)}{h+5 h * R I \_I N_{g}}}$ (in this case the denominator adds 5 times the normal holding cost for each rush orders waiting to be consolidated), THEN RUN SEQ $1 \mathrm{~N}$.

$\Rightarrow \quad$ IF TruckDispatchPolicy $=$ "DD” THEN

- IF $R I I N_{g}>0$ THEN RUN SEQ_1N.

$\Rightarrow \quad$ IF TruckDispatchPolicy $=$ "CD" THEN - IF $I \_I N_{g}>0$ AND there are available (not assigned) ILO trucks THEN RUN SEQ $1 N$. 


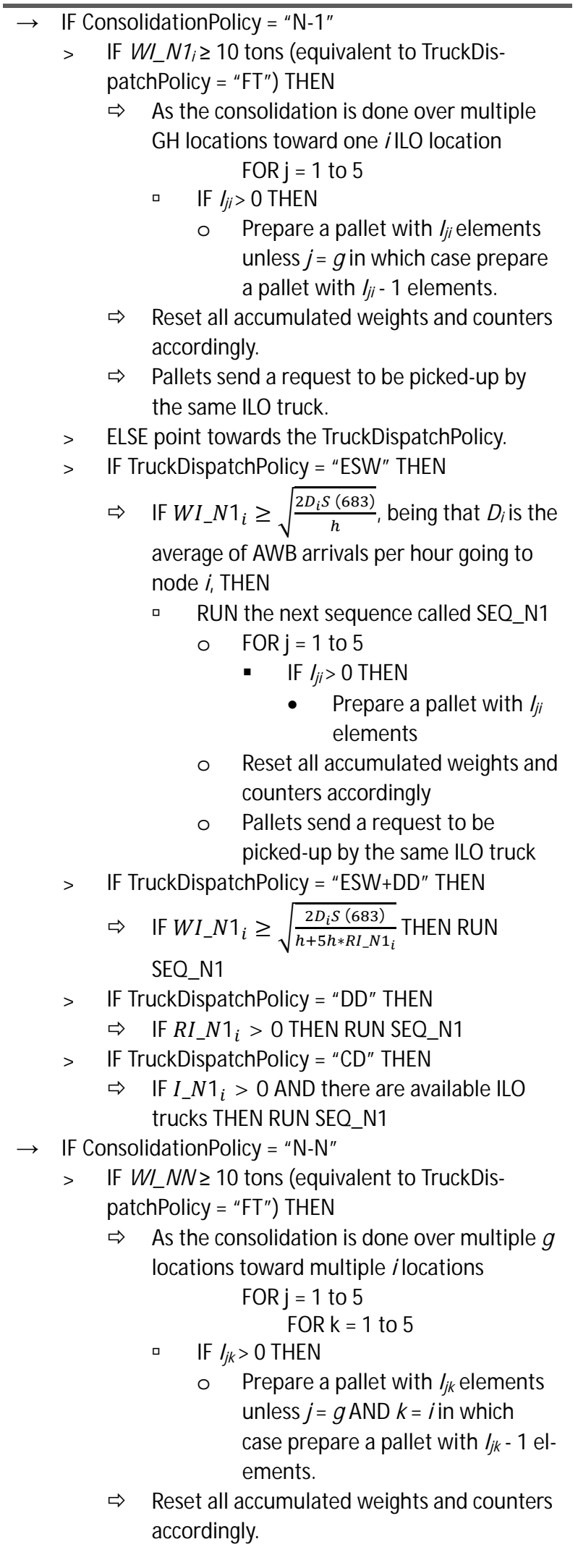

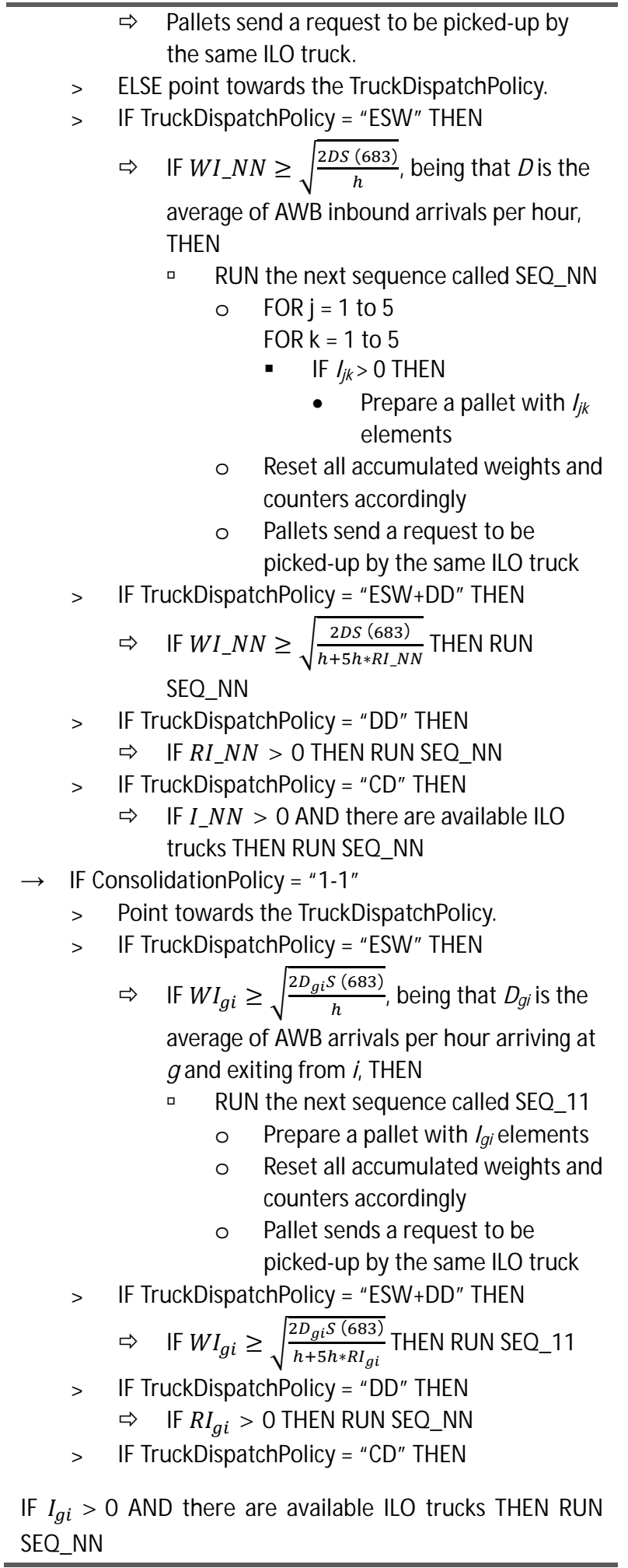

Table 7: Pseudo-code of the consolidation and truck dispatching policies' logic (Refer to Table A1 in the Appendix for the description of the variables in this pseudo-code). 
$\rightarrow \quad$ Loading and unloading times (LT) for ELO trucks depend on the type of container carrying the ELO consolidated shipment

$>\quad$ IF container is ULD THEN LT $=$ WELO/10 tons $* 15$ mins

$>\quad$ IF container is Pallet THEN LT $=$ WELO/ 10 tons * 60 mins

$>\quad \mathrm{IF}$ container is Combined THEN LT $=\mathrm{WELO} / 10$ tons $* 120$ mins

$\rightarrow$ LT for ILO trucks depend on the amount of weight that is being loaded or unloaded in the node, as some consolidation policies allow for multiple pick-up and/or delivery locations

$>\mathrm{LT}=\mathrm{W}_{\mathrm{g} /} / 10$ tons $* 30$ mins as $\mathrm{W}_{\mathrm{gi}}$ is what is being (un)loaded in a specific node

Table 8: Pseudo-code to define (un)loading times.

Finally, based on the current fleet of trucks used by the 5 ILOs selected for this study, 6 trucks were considered as the fleet that moves the AWBs between GH and ILO positions and vice-versa, using a collaborative approach [27], i.e. SALO was considered as the owner of the trucks and of this set of AWBs.

Following the previous conceptual design and logic presented, the modelling approach can be adapted to a different airport cargo hub different than the one presented here. Moreover, as it can be appreciated, by implementing the proposed elements, different shipment and truck policies can be evaluated considering for the first time not only the actors present in the system but also the variability which plays a key role in any real system allowing also revealing the emergent dynamics which cannot be revealed by other analytical technique.

\section{Results}

After a full-factorial experimental design was designed consisting of $4 \mathrm{CP}$ and $5 \mathrm{TP}$ for both inbound and outbound AWBs, resulting in a total of 400 experimental points. For each experimental setting, 10 replications were run with a duration of 40 days with 10 days of warm-up period.

The results revealed the following behaviour: policies that have more consolidation, e.g., FT, have a better performance in terms of total distance travelled by all 6 trucks than policies with lower consolidation efforts, e.g., $\mathrm{CD}$, but a bad performance in terms of AWB flow time and percentage of tardy AWBs.
On the other hand, the N-N policy had the worst performance in terms of distance but the best one in terms of time, whereas the opposite is true for the 1-1 policy. This might be caused by the fact that the N-N policy makes many visits to many locations in a single trip as it considers everything that needs to be moved, while the 1-1 policy only triggers a truck dispatch whenever there's enough material to be moved from one single point to another point.

For outbound shipments, the N-N policy seemed to result in the best compromise between distance travelled and flow time, as its performance in terms of percentage of tardy deliveries and average flow time was outstanding, compared with the relatively low increase in total kilometres travelled (see Table 9).

However, results from Table 9 suggest that the best policy for inbound shipments might be the 1-N policy, which considers all the shipments waiting to be moved from one GH location to the multiple ILO locations in the model.

\begin{tabular}{|c|c|c|c|c|c|c|}
\hline \multirow[b]{2}{*}{8} & \multicolumn{3}{|c|}{ Outbound } & \multicolumn{3}{|c|}{ Inbound } \\
\hline & 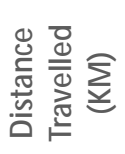 & 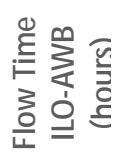 & 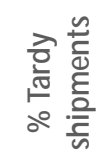 & 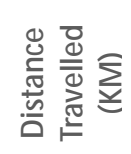 & 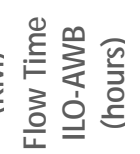 & 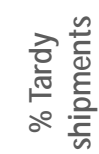 \\
\hline $1-1$ & 53,987 & 20.73 & $54.2 \%$ & 49,365 & 4.84 & $18.3 \%$ \\
\hline $1-N$ & 54,968 & 7.30 & $33.7 \%$ & 52,521 & 2.62 & $5.3 \%$ \\
\hline $\mathrm{N}-1$ & 55,971 & 7.19 & $27.4 \%$ & 54,113 & 2.65 & $5.3 \%$ \\
\hline $\mathbf{N}-\mathbf{N}$ & 56,466 & 2.77 & $5.7 \%$ & 65,384 & 2.32 & $3.9 \%$ \\
\hline
\end{tabular}

Table 9: Average results of applying different consolidation policies either for inbound or outbound AWBs.

Finally, Table 10 suggests that the best compromise between distance and delivery performance for outbound shipments was found with the ESW+RAWB policy. Interestingly, the RAWB policy on its own did not have a good performance in terms of delivery, even though it was designed to reduce the number of late deliveries from rush orders; whereas the best overall performance for inbound shipments was found with the ESW policy. 


\begin{tabular}{|c|c|c|c|c|c|c|}
\hline \multirow[b]{2}{*}{$=$} & \multicolumn{3}{|c|}{ Outbound } & \multicolumn{3}{|c|}{ Inbound } \\
\hline & 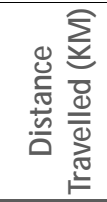 & 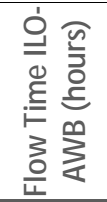 & 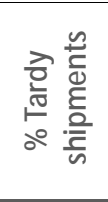 & 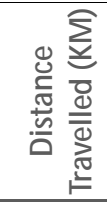 & 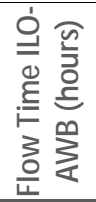 & 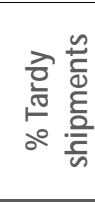 \\
\hline$C D$ & 75,591 & 1.89 & $6.1 \%$ & 96,600 & 1.97 & $3.9 \%$ \\
\hline ESW & 50,232 & 8.69 & $33.0 \%$ & 44,480 & 3.05 & $7.8 \%$ \\
\hline $\begin{array}{l}\text { ESW+ } \\
\text { RAWB }\end{array}$ & 51,127 & 7.39 & $26.9 \%$ & 45,892 & 2.93 & $6.9 \%$ \\
\hline $\mathbf{F T}$ & 49,118 & 16.30 & $47.2 \%$ & 42,718 & 3.89 & $11.7 \%$ \\
\hline RAWB & 50,630 & 13.22 & $37.9 \%$ & 47,144 & 3.69 & $10.7 \%$ \\
\hline
\end{tabular}

Table 10: Average results of applying different TP either for inbound or outbound AWBs.

\section{Conclusions and Future Research Directions}

The paper presents the main elements and conceptual design for developing a discrete-event simulation model of the landside logistic operations of a mega-hub airport considering for the first time elements that enable to evaluate the most common logistics problems of this type of infrastructure in a realistic fashion; we presented the case of Schiphol Airport in the Netherlands to exemplify the potential of this approach. A realistic representation of the road network of the airport as well as the (un)loading capacities of the ground handlers working inside the airport was developed. Several consolidation and truck-dispatching policies were proposed and tested in terms of performance. For the case presented, results suggest that truck-dispatching policies have a higher impact on performance than consolidation policies. Some of the results were counter-intuitive; thus, the platform developed can provide decision-makers excellent support for making decisions about how the best managing policy should be implemented depending on the objective pursued (economic, service, environmental).

A closer examination of the impact of combinations of consolidation and truck-dispatching policies is further needed to better understand their impact on performance. Furthermore, more research is needed regarding the impact of consolidation and truck-dispatching policies in other complex logistics systems as well and incorporating environmental considerations for evaluating which policy can have the best positive effect for reducing greenhouse emissions.

\section{Acknowledgements}

The authors would like to thank Dr. Thierry Verduijn and the Aviation Academy of the Amsterdam University of Applied Sciences for supporting this study as well as the Dutch Benelux Simulation Society (www.dutchbss.org) and EUROSIM for the dissemination of the results.

\section{References}

[1] IATA. Annual Review 2018. 2018.

[2] The World Bank. Connecting to Compete 2018: Trade Logistics in the Global Economy. Washington, DC, USA: 2018.

[3] European Comission. Statistical Pocketbook. 2018.

[4] Feng B, Li Y, Shen Z-J M. Air cargo operations: Literature review and comparison with practices. Transp Res Part C Emerg Technol 2015;56:263-80. DOI 10.1016/j.trc.2015.03.028

[5] Leung L C, Van Hui Y, Wang Y, Chen G. A 0-1 LP Model for the Integration and Consolidation of Air Cargo Shipments. Oper Res 2009;57:402-12. DOI 10.1287/opre.1080.0583

[6] Ou J, Hsu V N, Li C-L. Scheduling Truck Arrivals at an Air Cargo Terminal. Prod Oper Manag 2010;19:83-97. DOI 10.1111/j.1937-5956.2009.01068.x

[7] Mendoza-Dorantes E E, Alcaraz C Z, Mota M A M, Delahaye D. Simulating Airport Capacity: Mexico City Airport Case. ATOS 2015, 5th Int. Air Transp. Oper. Symp., 2015.

[8] Romero-Silva R, Shaaban S, Marsillac E, Laarraf Z. The impact of unequal processing time variability on reliable and unreliable merging line performance. Int J Prod Econ 2021;235:108108. DOI 10.1016/j.ijpe.2021.108108

[9] Higginson J K, Bookbinder J H. Policy recommendations for a shipment-consolidation program. J Bus Logist 1994;15:87-112.

[10] Goyal S K. Economic Order Quantity under Conditions of Permissible Delay in Payments. J Oper Res Soc 1985;36:335-8. DOI 10.2307/2582421

[11] Bookbinder J H, Higginson J K. Probabilistic modeling of freight consolidation by private carriage.

Transp Res Part E Logist Transp Rev 2002;38:305-18. DOI 10.1016/S1366-5545(02)00014-5

[12] Çetinkaya S, Mutlu F, Lee C-Y. A comparison of outbound dispatch policies for integrated inventory and transportation decisions. Eur J Oper Res 2006;171:1094112. DOI 10.1016/j.ejor.2005.01.019

[13] Çetinkaya S, Bookbinder J H. Stochastic models for the dispatch of consolidated shipments. Transp Res Part B Methodol 2003;37:747-68. DOI 10.1016/S0191-2615(02)00060-7. 
[14] Mutlu F, Çetinkaya S, Bookbinder J H. An analytical model for computing the optimal time-and-quantitybased policy for consolidated shipments. IIE Trans 2010;42:367-77. DOI 10.1080/07408170903462368

[15] Satır B, Erenay F S, Bookbinder J H. Shipment consolidation with two demand classes: Rationing the dispatch capacity. Eur J Oper Res 2018;270:171-84. DOI 10.1016/j.ejor.2018.03.016

[16] Çetinkaya S, Mutlu F, Wei B. On the service performance of alternative shipment consolidation policies. Oper Res Lett 2014;42:41-7. DOI 10.1016/j.orl.2013.11.003

[17] Battarra M, Cordeau J-F, Iori M. Pickup-and-Delivery Problems for Goods Transportation. In: Toth P, Vigo D, editors. Veh. Routing Probl. Methods Appl., Philadelphia,PA: SIAM; 2014, p. 161-91. DOI 10.1137/1.9781611973594.ch6

[18] Cook R A, Lodree E J. Dispatching policies for last-mile distribution with stochastic supply and demand. Transp Res Part E Logist Transp Rev 2017;106:353-71. DOI 10.1016/j.tre.2017.08.008

[19] Braekers K, Ramaekers K, Van Nieuwenhuyse I. The vehicle routing problem: State of the art classification and review. Comput Ind Eng 2016;99:300-13. DOI 10.1016/j.cie.2015.12.007

[20] Pillac V, Gendreau M, Guéret C, Medaglia A L. A review of dynamic vehicle routing problems. Eur J Oper Res 2013;225:1-11. DOI /10.1016/j.ejor.2012.08.015

[21] Kelton W D, Smith J S, Sturrock D T. Simio and Simulation: Modeling, Analysis, Applications. 1st ed. Sewickley, PA: Simio LLC; 2014.

[22] Air Cargo Netherlands. Ground Handler members of ACN 2018. http://www.acn.nl/sectoren/ afhandelaars/?lang=en (accessed October 23, 2018).

[23] Green L V, Kolesar PJ, Whitt W. Coping with TimeVarying Demand When Setting Staffing Requirements for a Service System. Prod Oper Manag 2007;16:13-39. DOI 10.1111/j.1937-5956.2007.tb00164.x.

[24] Selinka G, Franz A, Stolletz R. Time-dependent performance approximation of truck handling operations at an air cargo terminal. Comput Oper Res 2016;65:164-73. DOI 10.1016/j.cor.2014.06.005

[25] Yan S, Chen C-H, Chen C-K. Short-term shift setting and manpower supplying under stochastic demands for air cargo terminals. Transportation (Amst) 2008;35:425-44. DOI 10.1007/s11116-007-9151-7

[26] Burdzik R, Cieśla M, Sładkowski A. Cargo Loading and Unloading Efficiency Analysis in Multimodal Transport. PROMET -Traffic\&Transportation 2014;26:323-31. DOI 10.7307/ptt.v26i4.1356

[27] Gansterer M, Hartl R F. Collaborative vehicle routing: A survey. Eur J Oper Res 2018;268:1-12. DOI 10.1016/j.ejor.2017.10.023

\section{Appendix}

- Weight accumulated for inbound AWBs going from GH g to ILO i (1-1 policy): WI gi

- Weight accumulated for inbound AWBs whose initial node is $\mathrm{g}(1-\mathrm{N})$ : WI_ $1 \mathrm{~N}_{\mathrm{g}}$

- Weight accumulated for inbound AWBs whose final node is $\mathrm{i}(\mathrm{N}-1)$ : $\mathrm{WI} \mathrm{N}_{\mathrm{i}}$

- Weight accumulated for inbound AWBs in all GH nodes going to all ILO nodes (N-N): WI_NN

- Number of inbound AWBs going from GH g to ILO I (11 policy): $I_{g i}$

- Number of inbound AWBs whose initial node is g (1N): I $1 \mathrm{~N}_{\mathrm{g}}$

- Number of inbound AWBs whose final node is $\mathrm{i}(\mathrm{N}-\mathrm{1})$ : I_N1

- Number of inbound AWBs in all GH nodes going to all ILO nodes (N-N): I NN

- Number of inbound rush AWBs going from $\mathrm{GH} g$ to ILO I (1-1 policy): RI ${ }_{\text {gi }}$

- Number of inbound rush AWBs whose initial node is $g$ (1-N): RI_1 $1 \mathrm{~N}_{\mathrm{g}}$

- Number of inbound rush AWBs whose final node is i (N-1): RI_N1 $1_{\mathrm{i}}$

- Number of inbound rush AWBs in all GH nodes going to all ILO nodes (N-N): RI_NN

- Weight accumulated for outbound AWBs going from ILO i to GH g (1-1 policy): W ig $_{\text {, }}$

- Weight accumulated for outbound AWBs whose initial node is i (1-N): WO_1Ni

- Weight accumulated for outbound AWBs whose final node is $\mathrm{g}(\mathrm{N}-1)$ : WO_N1

- Weight accumulated for outbound AWBs in all ILO nodes going to all GH nodes (N-N): WO_NN

- $\quad$ Number of outbound AWBs going from ILO i to GH g (1-1 policy): $0_{i g}$

- $\quad$ Number of outbound AWBs whose initial node is i (1$\mathrm{N}): 0 \_1 \mathrm{~N}_{\mathrm{i}}$

- Number of outbound AWBs whose final node is g (N1): $\mathrm{O}_{-} \mathrm{N}_{\mathrm{g}}$

- Number of outbound AWBs in all ILO nodes going to all GH nodes (N-N): O_NN

- Number of outbound rush AWBs going from ILO $i$ to GH g (1-1 policy): RO ig

- Number of outbound rush AWBs whose initial node is $\mathrm{i}(1-\mathrm{N})$ : RO_1 $\mathrm{N}_{\mathrm{i}}$

- Number of outbound rush AWBs whose final node is $\mathrm{g}(\mathrm{N}-1): \mathrm{RO}_{-} \mathrm{N}_{\mathrm{g}}$

- Number of outbound rush AWBs in all ILO nodes going to all GH nodes (N-N): RO_NN

Table A1: Set of variables for consolidation and truck dispatching policies' logic. 